\title{
Health Practitioner Regulation: Has the National Law Produced National Outcomes in Serious Disciplinary Matters?
}

This is a pre-publication version of an article which will appear in (2019) 47(4) Federal Law Review.

\author{
Jenni Millbank
}

\section{Abstract}

Since 2010 a national scheme regulates the registration, accreditation and discipline of health professionals in Australia (the National Law). This research examines disciplinary cases from Tribunals nationwide to address the question: Has the national regulation of health professionals produced consistency in outcomes in serious cases of professional misconduct? All publicly available Australian Tribunal level decisions concerning complaints of serious misconduct and/or impairment brought against the five most populous regulated health professions (nurses and midwives, doctors, psychologists, pharmacists, and dentists) were analysed for the period 1 July 2010 to 30 June 2017. Each case was coded by reference to a typology of misconduct, practitioner characteristics, and outcome, allowing for comparisons to be drawn both as between the professions and as between jurisdictions. Major disparities were identified in outcomes across the professions, with doctors being subject to less severe outcomes than other professions, in particular in comparison with nurses, even when the same main head of misconduct was in issue. Marked disparities were also identified between outcomes in different states and territories, suggesting that the National Law is not being applied in a uniform manner. This article examines these disparities and explores possible contributing factors.

\footnotetext{
- Distinguished Professor of Law, UTS. This research was funded by the UTS Law Health Justice Research Centre and UTS PEP scheme. Thanks to David Carter, Frances Taylor, Mary-Therese Daniel and Jenny Boland for comments on previous versions of this paper, to research associate Eloise Chandler, Matej Marek for statistical analysis, and to Cindy Lam, Ruby Wawn and Ellen O'Brien for research assistance. The author has been a part time member of the NSW Civil and Administrative Tribunal (NCAT), Occupational Division, since 2015. This role involves presiding in health disciplinary matters, including seven cases that ultimately comprised part of the data set. To ensure integrity of the coding, the author did not undertake any coding of those seven cases nor discuss them with research assistants. The views expressed in this article are those of the author alone and do not represent NCAT. NCAT had no role in the design or conduct of this research.
} 


\section{Introduction}

Since 2010 a national scheme regulates the registration, accreditation and discipline of health professionals in Australia (the National Law). The scheme began with 10 registered health professions, expanding to 14 professions in 2012 and then 15 from 1 December 2018. While there is some jurisdictional variation in terms of which agencies undertake disciplinary investigations, and slight differences in definitions and legislative provisions in some States and Territories, the scheme is a national one which introduced broadly uniform rules addressing unsatisfactory performance, unprofessional conduct and misconduct. The scheme regulates over 700,000 health professionals at the time of writing.

This research evaluates one aspect of the disciplinary process under the National Law: Tribunal level determinations. Only matters that are designated as serious, that is, as involving a prima facie indication of de-registrable conduct, are referred to the various State and Territory based Tribunals which then apply almost identical substantive legislative provisions. There is a serious gap in knowledge concerning Tribunal outcomes because, unlike data on complaints under the National Law, Tribunal data is not collated in a consistent manner and is not centralised. There is no publicly accessible data on Tribunal level cases and outcomes that presents complaint type, profession, or other significant factors such as gender or age. In short, the more serious the matter, the less is known about types of misconduct and ultimate outcomes imposed.

In this study all publicly available Australian Tribunal level decisions concerning complaints of serious misconduct and/or impairment brought against the five most populous regulated health professions (nurses and midwives, doctors, psychologists, pharmacists, and dentists) were gathered and analysed for the seven-year period 1 July 2010 to 30 June 2017, comprising 794 matters in total. Each case was coded by reference to a typology of misconduct, practitioner characteristics, and outcome, allowing for comparisons to be drawn both as between the professions and as between jurisdictions.

Major disparities were identified in outcomes across the professions, with doctors being subject to less severe outcomes than other professions, in particular in comparison with nurses, even when the same main head of misconduct was in issue. Marked disparities were also identified between outcomes in different states and territories, suggesting that the 
National Law is not being applied in a uniform manner. This article examines these disparities and explores possible contributing factors.

First, this article outlines the national law and then places an overview of findings in the context of what is already known from previous Australian and New Zealand research on complaint data and disciplinary cases. The sections that follow explore the novel findings of the study and discuss possible explanations for major areas of variation in outcomes discovered.

\section{The National Law}

On 1 July 2010 the Australian Health Practitioner Regulation Agency (AHPRA) was created as a single national oversight agency for the registration, accreditation and disciplining of health professionals in Australia. ${ }^{1}$ This was a vast and complex undertaking, consolidating eight separate regulatory systems, comprising 74 pieces of legislation, 20 accrediting bodies and between 85 and 97 separate health practitioner registration boards across the country. ${ }^{2}$ The development of the National Health Practitioner Regulation Law (the National Law) is a particularly striking achievement given the 'breakneck' speed with which it was undertaken. ${ }^{3}$ The report that recommended the scheme by the Productivity Commission was initiated by the Commonwealth in mid-2004, released in January 2006, ${ }^{4}$ and led to a detailed Intergovernmental Agreement on the scheme that was entered into in March $2008,{ }^{5}$ and

\footnotetext{
${ }^{1}$ For background, see Ian Freckelton, 'Regulation of Health Practitioners: National Reform in Australia' (2010) 18 Journal of Law and Medicine 207; for a comprehensive overview of how the different institutions fit together (including the 'co-regulatory' approach of NSW to discipline, which has now extended to Queensland) see Gabrielle Wolf, 'Regulation of Health Professionals' in Anne-Maree Farrell, John Devereux, Isabel Karpin and Penelope Weller (eds) Health Law: Frameworks and Context (Cambridge University Press, 2017) 78.

2 For background see: COAG Health Council, 'The Independent Review of the National Registration and Accreditation Scheme for Health Professionals' (Communique, 7 August 2015).

${ }^{3}$ See Kerry Breen, 'National Registration Scheme at 5 Years: Not What It Promised' (2016) 40 Australian Health Review 674.

${ }^{4}$ Australian Government, Productivity Commission, Australia's Health Workforce, Research Report (2005) <http://www.pc.gov.au/inquiries/completed/health-workforce>.

5 Council of Australian Governments, Intergovernmental Agreement for a National Registration and Accreditation Scheme for the Health Professions (2008) <http://www.ahpra.gov.au/About-AHPRA/MinisterialDirectives-and-Communiques.aspx> (COAG).
} 
implemented nation-wide through legislative changes in all jurisdictions in 2009 and $2010 .{ }^{6}$ The scheme currently regulates 15 health professions (Aboriginal and Torres Strait Islander Health Practice, Chinese Medicine, Chiropractic, Dental, Medical, Medical Radiation Practice, Nursing and Midwifery, Occupational Therapy, Optometry, Osteopathy, Pharmacy, Physiotherapy, Podiatry, Psychology and most recently Paramedicine) comprising over 700,000 registrants. $^{7}$

Prior to the National Law, the state and territory based approach to health regulation had been marked by inconsistency across and within different health professions, with many allied health practitioners not included within state disciplinary schemes at all, meaning a significant degree of self-regulation among numerous conventional and allied health professional groups (sometimes with multiple groups for each profession). Some practitioners, such as Chinese Medicine, were included within professional health regulation in some states but not others. Demands for greater external oversight and procedural fairness protections meant that specialist tribunals - with a mix of health professional, lay and legal membership - were created to address serious disciplinary breaches; and these proliferated within a fragmented local and national frame. So for example, prior to the National Law, a pharmacist who stole and consumed prescription drugs from his place of work would face different substantive misconduct provisions and disciplinary processes in each state, and these would be different again to the provisions and processes faced by a nurse who did exactly the same thing in her workplace.

At the highest level of oversight, the regulation of health practitioners was plagued by difficulties in workforce mobilisation: on the one hand capable professionals were restrained

\footnotetext{
${ }^{6}$ Enacted through: Health Practitioner Regulation National Law Act 2009 (QId); Health Practitioner Regulation National Law Act 2009 (NSW); Health Practitioner Regulation National Law (Vic) Act 2009 (Vic); Health Practitioner Regulation National Law (South Australia) Act 2010 (SA); Health Practitioner Regulation National Law (WA) Act 2010 (WA); Health Practitioner Regulation National Law (ACT) Act 2010 (ACT); Health Practitioner Regulation National Law (Tasmania) Act 2010 (Tas); Health Practitioner Regulation (National Uniform Legislation) Act 2010 (NT).

${ }^{7}$ See AHPRA, What We Do <http://www.ahpra.gov.au/About-AHPRA/What-We-Do.aspx> including infographics explaining the complex inter-relation of national boards with the Councils and Ombudsmen in co-regulatory jurisdictions.
} 
from being able to work nationally, and, on the other, rogue and incompetent professionals evaded regulation by shifting across jurisdictions. It was the former of these concerns, an efficient mobile workforce, which dominated the Productivity Commission report; while the latter concern of evasive poorly performing, unethical and unregulated practitioners dominated media reports and regulator concerns. ${ }^{8}$

While all the States and Territories joined the National Law scheme, they did so with variations. Most significantly, NSW maintained its own well established complaint investigation and referral disciplinary system within which to apply the law. NSW was thus designated a 'co-regulatory' jurisdiction and Queensland followed this approach in $2014 .{ }^{9}$

The National Law objects reflect its genesis, providing a national registration and accreditation scheme for health practitioners (and students) in order:

(a) to provide for the protection of the public by ensuring that only health practitioners who are suitably trained and qualified to practise in a competent and ethical manner are registered; and

(b) to facilitate workforce mobility across Australia by reducing the administrative burden for health practitioners wishing to move between participating jurisdictions or to practise in more than one participating jurisdiction; and

(c) to facilitate the provision of high quality education and training of health practitioners; and

(d) to facilitate the rigorous and responsive assessment of overseas-trained health practitioners; and

(e) to facilitate access to services provided by health practitioners in accordance with the public interest; and

(f) to enable the continuous development of a flexible, responsive and sustainable Australian health workforce and to enable innovation in the education of, and service delivery by, health practitioners. ${ }^{10}$

\footnotetext{
${ }^{8}$ See Freckelton above n 1, and more latterly: COAG, Final Report - A National Code of Conduct for Health Care Workers (2015).

${ }^{9}$ See Belinda Bennett et al, 'Australia's National Registration and Accreditation Scheme for Health Practitioners: A National Approach to Polycentric Regulation?' (2018) 40 Sydney Law Review 159.

${ }^{10}$ Health Practitioner National Law 2009 (Qld) s 3(2).
} 
Possibly because of concern that 'access to health services' or the public interest would be seen as competing with or overriding safety considerations, ${ }^{11}$ both NSW and Queensland added a further objects section, section $3 \mathrm{~A}$, providing that the 'health and safety of the public' is the 'paramount guiding principle'. The 'protection of the public' is also expressed as a 'primary consideration' in balancing the objects of the scheme under the Regulatory Principles for the National Scheme. ${ }^{12}$

The vast majority of formal complaints against health practitioners (which may be made as mandatory or voluntary 'notifications' under the National Law) are handled within the professional Board system, in which matters are channelled into health or performance and conduct 'pathways' by Boards within each profession if found to have some basis. ${ }^{13}$ Practitioners with health issues are managed by an 'impaired registrants' panel' while those with unsatisfactory professional performance or illegal, unethical or unprofessional 'conduct' face a 'performance and professional standards' panel. Each pathway may entail 'immediate action' including the imposition of conditions on a practitioner's registration or, if assessed as a serious risk to the public, suspension. ${ }^{14}$ The most serious matters, those which are characterised as prima facie so significant as to be likely to lead to deregistration, are referred to a legally-headed disciplinary tribunal: the only body with the power to deregister a practitioner altogether.

Under the National Law unprofessional conduct or unsatisfactory professional performance (which are combined under the category unsatisfactory professional conduct in NSW) ${ }^{15}$ may

\footnotetext{
${ }^{11}$ See Katie Elkin, 'Medical Practitioner Regulation: Is It All About Protecting the Public? (2014) 21 Journal of Law Medicine 682, and discussion below.

12 https://www.ahpra.gov.au/About-AHPRA/Regulatory-principles.aspx Principle 3.

${ }^{13}$ For a detailed discussion of how the pathways for complaints handling occur, before and after the National Law, see: Claudette Satchell et al, 'Approaches to Management of Complaints and Notifications about Health Practitioners in Australia' (2016) 40(3) Australian Health Review 311.

${ }^{14}$ Compare Health Practitioner Regulation National Law Act 2009 (Qld) s 156 (a Board may take action if necessary to protect public health and safety) with Health Practitioner Regulation National Law Act 2009 (NSW) s 150 (Council must take action if appropriate to protect health and safety).

${ }^{15}$ For a comparison of the NSW and National provisions see Mary Chiarella et al, 'Survey of Quasi-Judicial Decision-Makers in NSW and The National Registration Scheme for Health Practitioners' (2018) 25 Journal of Law and Medicine 357, Appendix A.
} 
rise to the higher level of professional misconduct either by reason of severity of conduct, or repetition, or both. A Board must refer a matter to the 'responsible tribunal' if it reasonably believes that the practitioner has behaved in a way that constitutes professional misconduct (or if the practitioner's registration was improperly obtained because of false or misleading information, or if a panel established by the Board requires it to do so). ${ }^{16}$ Tribunals are chaired by a legal member and usually made up of one or two members of the same profession as the health practitioner whose behaviour is under review, in addition to a non-practitioner or 'community' member. In NSW, Victoria, Queensland, the ACT and NT the responsible Tribunal is currently the Civil and Administrative Tribunal; in WA it is the State Administrative Tribunal and in Tasmania and South Australia it is the Health Practitioners Tribunal. ${ }^{17}$

If unprofessional conduct is proved, a Tribunal may impose conditions or issue a reprimand or caution or, in certain circumstances, a fine. Removal from practice through deregistration or suspension is only available if misconduct is proved (or if the practitioner is not competent to practise or is unsuitable or, by reason of criminal conviction, unfit in the public interest to practise). While some Tribunals use terms such as 'penalty' or 'charge', the National Law is replete with reference to protecting the public from harm, and from being placed at risk, Qld and NSW have the paramount object of safety of the public, and the jurisprudence from appellate level courts and the Tribunals themselves stress that orders are not intended to be punitive, but to protect the public. ${ }^{18}$

Although the category 'removal from practice' is commonly used by researchers and policymakers, there is a significant difference in severity between deregistration and suspension orders. A suspension is finite; it must be limited in time and when that time passes,

\footnotetext{
${ }^{16}$ Health Practitioner Regulation National Law Act 2009 (Qld) s 193.

${ }^{17}$ Victoria, Queensland and WA heard health matters within a generalist administrative tribunal before and after the advent of the National Law. In the ACT and NT there was a specialist health practitioner tribunal at the time of the implementation of the National Law, but they later shifted to a generalist tribunal (in 2010 and 2015 respectively). SA and Tasmania introduced a specialist tribunal to coincide with the National Law. NSW amalgamated over a dozen profession-specific tribunals into a generalist tribunal in 2014 .

18 See e.g.: Health Care Complaints Commission v Litchfield (1997) 41 NSWLR 630, 637; Health Care Complaints Commission v Do [2014] NSWCA 307; Sudath v Health Care Complaints Commission [2012] NSWCA 171; Craig v Medical Board of South Australia [2001] SASC 169; Medical Board of Australia v Myers [2014] WASAT 137; Medical Board of Australia v Petrovic [2011] VCAT 795.
} 
registration is automatically restored. In contrast, after an order of deregistration the practitioner must reapply to the Board (or in NSW to the Tribunal ${ }^{19}$ ), sometimes only after a set period, and satisfy it that they are now fit to practise. ${ }^{20}$ This is a heavy practical and legal burden, as the passage of time alone does not establish fitness and the practitioner bears the onus of proving that they are now safe to return to practice.

A prohibition order, preventing the practitioner from providing one or more other health services for a period of time or permanently, is available only if the practitioner is removed from practice ${ }^{21}$ (and in NSW is only available if the respondent is assessed as posing a substantial risk to the health of members of the public ${ }^{22}$ ). Such an order is used to prevent a practitioner from moving into other forms of unregistered health practice, and might be imposed for example, to prevent a drug dependent practitioner from working as a pharmacy assistant or an osteopath found to have engaged in sexual misconduct from setting up a massage practice.

\section{Overview of the case set}

All publicly available Australian Tribunal level decisions concerning complaints of serious misconduct and/or impairment brought against the five most populous regulated health professions were gathered from period 1 July 2010 to 30 June 2017. The period was chosen to correlate with advent of the operation of the National Law. The professions were, in order from most to least populous: nurses and midwives, doctors, psychologists, pharmacists, and dentists. ${ }^{23}$

\footnotetext{
${ }^{19}$ See Health Practitioner Regulation National Law (NSW) 2009 (NSW) s 149E.

20 See discussion in Laurie Warfe, 'Determining the Risk of Recidivism in Previously De-Registered Health Practitioners' (2013) 21 Journal of Law and Medicine 67.

${ }^{21}$ Health Practitioner Regulation Act 2009 (Qld) s 196(4)(b).

${ }^{22}$ Health Practitioner Regulation National Law (NSW) 2009 (NSW) s 149C(5), (5A).

${ }^{23}$ While nurses and midwives are actually separate professions, they are regulated by the same Board and are often addressed together in research and policy literature and are grouped together in this analysis for that reason.
} 
Relevant decisions were identified through a search of all previous and current Tribunal sets within the Austlll database, augmented by cases from the various Tribunal websites. Appeal decisions, reinstatement decisions and non-disciplinary cases were excluded. The dataset comprised 794 cases $^{24}$, of which 35 per cent (278) were determined in New South Wales (NSW); 20 per cent (159) in Western Australia (WA), 17 per cent (134) in Queensland (Qld), 15 per cent (118) in Victoria, and 8 per cent (66) in South Australia (SA). The overrepresentation of cases from WA compared to the more populous states of Victoria and Queensland reflects differential case release policies in these jurisdictions, as neither Queensland nor Victoria release all decided cases. Cases determined in the Australian Capital Territory (ACT), Northern Territory (NT) and Tasmania cumulatively amounted to five percent of the dataset overall (accounting for 16, 4 and 18 cases respectively) accurately reflecting their lower populations. There were approximately equal numbers of cases found across each of the seven financial years.

The coding instrument recorded case and respondent attributes, the type/s of misconduct alleged, whether proved, and the relevant disciplinary outcome. ${ }^{25}$ Respondent attributes were: profession; gender; legal representation; and certain identified 'risk' factors from

\footnotetext{
${ }^{24}$ The data was organised per respondent, as opposed to organised by decision per se, so any procedural, or subsequent decisions flowing from the same matter was treated in the dataset as one case. Where on occasion proceedings against two or more respondents were heard together, separate entries were made for each respondent so as to record the complaints made against each professional and final outcome. After the dataset was closed four further decisions were provided by the ACT Tribunal but were not able to be included in the analysis. For completeness, those cases involved two doctors (one of whom relinquished registration following a prescription complaint, the other was deregistered following a finding of sexual misconduct) and two psychologists (one of whom was cautioned following treating multiple members of the same family, and the other received conditions following sexual misconduct).

${ }^{25}$ The investigator and research assistants cross-checked coding for consistency at several junctures throughout the research. The findings were analysed for statistical significance using SPSS version 25 , and an alpha value of 0.05 . Statistical significance was established for all key findings reported in this paper with the exception of the differential rates of deregistration of the professions in sexual misconduct matters, which had too few cases to establish significance. The $p$ value of key findings is noted in footnotes throughout.
} 
previous studies (over 60 years of age; ${ }^{26}$ trained outside Australia; ${ }^{27}$ engaged in sole or isolated practice; ${ }^{28}$ subject to criminal proceedings; repeat incidents ${ }^{29}$ ).

The type of allegation was coded building on the 'typologies of misconduct' developed by Katie Elkin and colleagues. ${ }^{30}$ This utilises five main categories or heads of misconduct, with subtypes within each, set out in Table 1 below. Following Elkin et al, the main head of misconduct was defined as the behaviour of 'most concern' to the Tribunal, ascertained through close reading of the text of the decision. Decisions ranged from 10 to over 100 pages in length, but were generally around 30 pages long. Elkin et al note that 'professional misconduct is often multilayered rather than confined to a single isolated breach' ${ }^{31}$ and this was reflected in the fact that most matters involved multiple allegations.

Table 1: Misconduct Typologies including subtypes

\begin{tabular}{|c|c|c|c|c|c|}
\hline $\begin{array}{l}\text { Main Head } \\
\text { of } \\
\text { Misconduct }\end{array}$ & $\begin{array}{l}\text { Illegal or } \\
\text { unethical } \\
\text { prescription or } \\
\text { provision of drugs }\end{array}$ & Impairment & Inappropriate clinical care & Sexual misconduct & Other \\
\hline Subtypes & $\begin{array}{l}\text { 1.To self } \\
\text { 2.To others }\end{array}$ & $\begin{array}{l}\begin{array}{l}\text { 1.Substance } \\
\text { abuse }\end{array} \\
\text { 2.Mental } \\
\text { illness } \\
\text { 3.Physical } \\
\text { impairment } \\
\text { 4.Cognitive } \\
\text { impairment }\end{array}$ & $\begin{array}{l}\text { 1.Treatment } \\
\text { (inappropriate/inadequate) } \\
\text { 2.Failure to refer to a medical } \\
\text { practitioner/hospital/ambulance } \\
\text { 3.Diagnosis (missed, delayed, or } \\
\text { incorrect) }\end{array}$ & $\begin{array}{l}\text { 1. Relationship with } \\
\text { patient } \\
\text { 2.Inappropriate } \\
\text { sexual contact } \\
\text { during treatment }\end{array}$ & $\begin{array}{l}\text { 1.Non-sexual misconduct } \\
\text { 2.Inappropriate conduct not re } \\
\text { patient } \\
\text { 3.Breach of registration conditions } \\
\text { 4.Failure to obtain informed } \\
\text { consent } \\
\text { 5.Failure to maintain adequate } \\
\text { records } \\
\text { 6.Breach of Privacy }\end{array}$ \\
\hline
\end{tabular}

${ }^{26}$ See eg Anna Ryan, Lay San Too, and Marie Bismark, 'Complaints about Chiropractors, Osteopaths, and Physiotherapists: A Retrospective Cohort Study of Health, Performance, and Conduct Concerns' (2018) 26(12) Chiropractic and Manual Therapies 1.

${ }^{27}$ Katie Elkin, Matthew Spittal, and David Studdert, 'Risks of Complaints and Adverse Disciplinary Findings against International Medical Graduates in Victoria and Western Australia' (2012) 197 Medical Journal of Australia 448 but cf Marie Bismark, Matthew Spittal, and David Studdert, 'Prevalence and Characteristics of Complaint-Prone Doctors in Private Practice in Victoria' (2011) 195 Medical Journal of Australia 25 finding overseas trained doctors had lower odds of being complaint-prone.

${ }^{28}$ Marie Bismark et al, 'Identification of Doctors at Risk of Recurrent Complaints: A National Study of Healthcare Complaints in Australia' (2013) 22 BMJ Quality and Safety 532.

29 Ibid.

${ }^{30}$ Katie Elkin et al, 'Doctors Disciplined for Professional Misconduct in Australia and New Zealand, 2000-2009' (2011) 194 Medical Journal of Australia 452.

${ }^{31}$ Id, 455. 


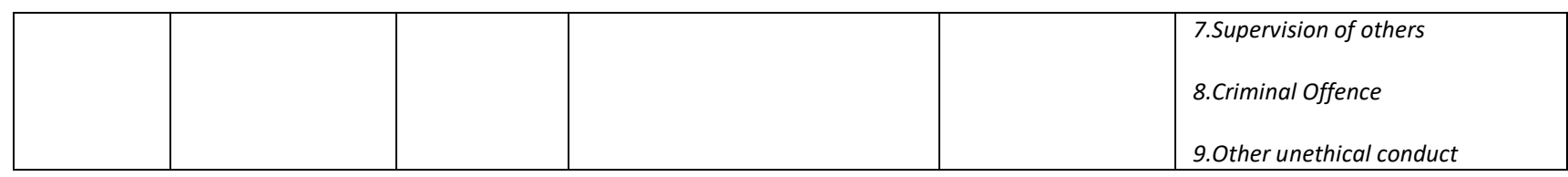

Outcomes for proved conduct were coded and categorised for severity.

Removal from practice involved:

- deregistration;

- suspension;

- prohibition orders.

Conditions on practice were:

- education/mentoring;

- counselling;

- supervision;

- health conditions;

- restricted practice;

- other conditions.

Non-restrictive sanctions were:

- reprimand;

- fine;

- caution.

While deregistration and suspension are mutually exclusive, and deregistration and conditions are mutually exclusive, other orders can be made in combination, for example a period of suspension followed by conditions, multiple conditions in tandem, or deregistration and reprimand.

It is important to recall that these cases are the product of three 'interrelated elements': the amount of underlying misconduct in each profession, the rate at which it is reported, and the rate at which it is referred on to Tribunals. ${ }^{32}$ This study is therefore not on the prevalence of misconduct per se, but rather on regulatory responses, and in particular, the question of consistency in outcomes of the most serious disciplinary matters determined since the advent of the National Law. With this in mind, draft findings were sent to the division heads of the health professional discipline section of each of the eight Tribunals in the study, and comment

\footnotetext{
32 Ibid.
} 
was invited on the areas of identified inconsistency. Members from three Tribunals, NSW, ACT and WA, responded. Those responses are incorporated in the later discussion.

When taken within the context of AHPRA data on the numbers of registered practitioners from the five professions over the corresponding seven-year period, doctors were significantly over-represented in the disciplinary cases, appearing at more than double their proportion of the practitioner population, while pharmacists, dentists and psychologists were also over-represented, appearing at almost double their proportion of practitioners. In contrast, nurses and midwives while numerous in raw terms, appeared at half their proportion of practitioners. ${ }^{33}$

The majority of respondents were male ( $n=526,66.2$ per cent). This disproportion however is much starker when national data on the gender breakdown of the professions is taken into account, as only the medical profession has more men than women practising. Based on AHPRA data over this seven-year period, men comprised only 23.2 per cent of registered practitioners across these five professions. Figure 1 below disaggregates each profession to demonstrate where gender disproportions appear most starkly in the case set; for example, female dental practitioners appear in the misconduct cases at the rate of less than one quarter their representation in the profession, while female doctors and pharmacists appear at the rate of around one third their populations; in contrast male nurses appear at four times their rate of the professional population. ${ }^{34}$

Figure 1. Profession Breakdown by Gender

\footnotetext{
${ }^{33}$ Doctors comprised 39.9 per cent of the misconduct cases, but only 18.4 per cent of membership across the five registered professions. Dentists made up 6.5 per cent of the dataset and 3.8 per cent of the professions; pharmacists 9.4 per cent of the dataset and 5.2 per cent of the professions, psychologists 9.3 per cent of the dataset and 5.9 per cent of the professions and nurses and midwives 34.8 per cent of the dataset but 66.7 per cent of the population of the professions. The proportion of each of the five professions in the professional population was calculated by using data from each financial year 2010-2017, averaged, drawn from APHRA Annual Reports. The reports record the numbers of registrants for each registered profession, with a gender breakdown provided for most years, see: AHPRA, Annual Report 2010-11 (2011), Annual Report 2011-2012 (2012), Annual Report 2012-2013 (2013), Annual Report 2013-4 (2014), Annual Report 2014-2015 (2015), Annual Report 2015-2016 (2016), Annual Report 2016-2017 (2017), all available at https://www.ahpra.gov.au/Publications/Annual-reports.aspx (accessed 22 March 2019).

${ }^{34}$ The relationship between gender and appearance in the misconduct dataset was established as statistically significant with a $\mathrm{p}$ value of 0.001 .
} 


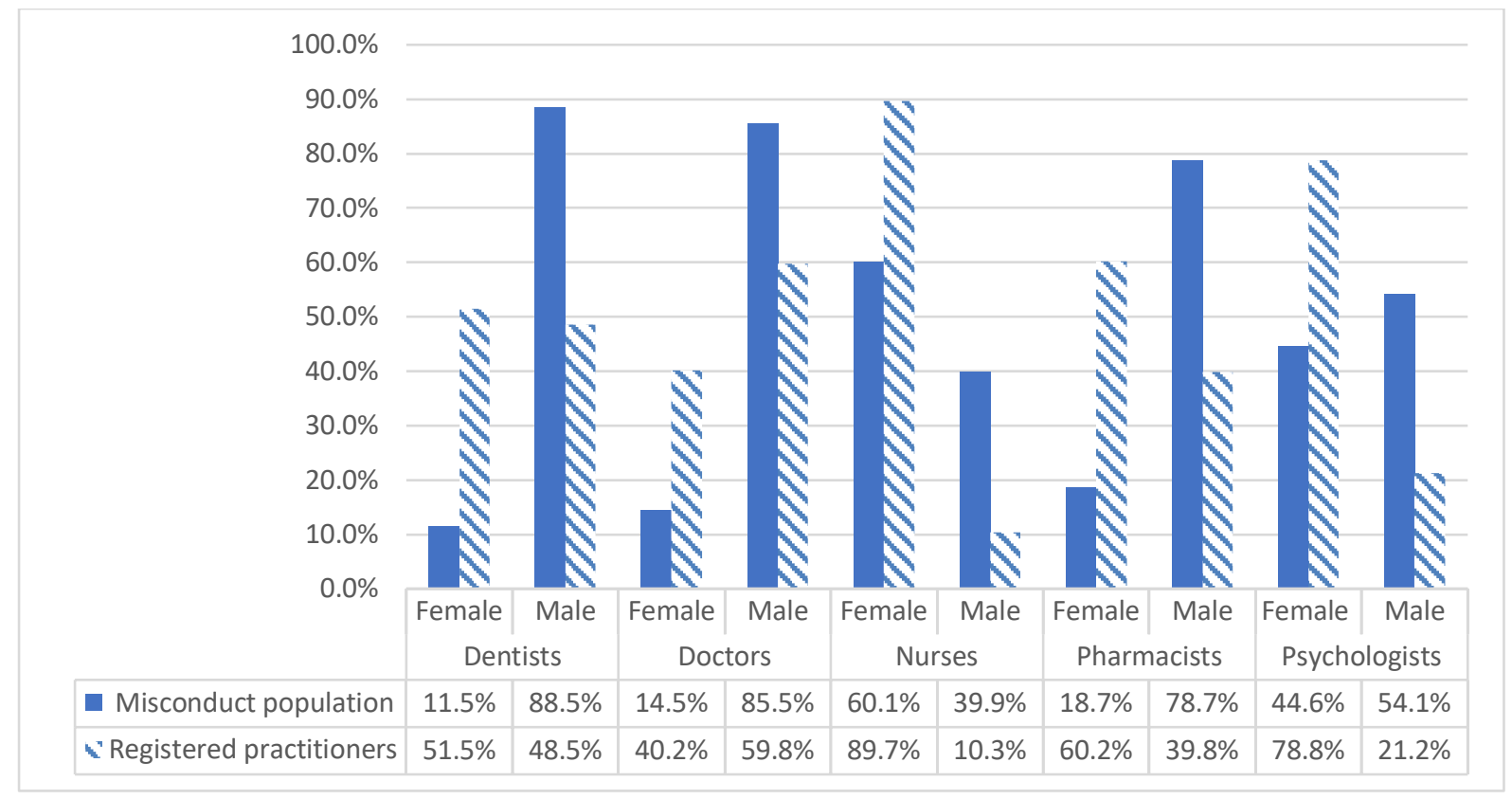

The most common type of misconduct was inappropriate clinical care (25.7 per cent), followed by sexual misconduct and illegal/unethical prescription or provision of drugs which were equal in number, amounting to 20 per cent of matters respectively. Impairment was the least likely to feature as the main head of complaint, appearing in only 4.8 per cent of matters, reflecting the likelihood of diversion of such complaints into 'health pathways' (although impairment frequently appeared as a secondary complaint in prescription matters). The 'Other' head of misconduct was substantial, comprising 29.7 per cent of cases in which the sub types of matter were diverse and not readily categorised. 


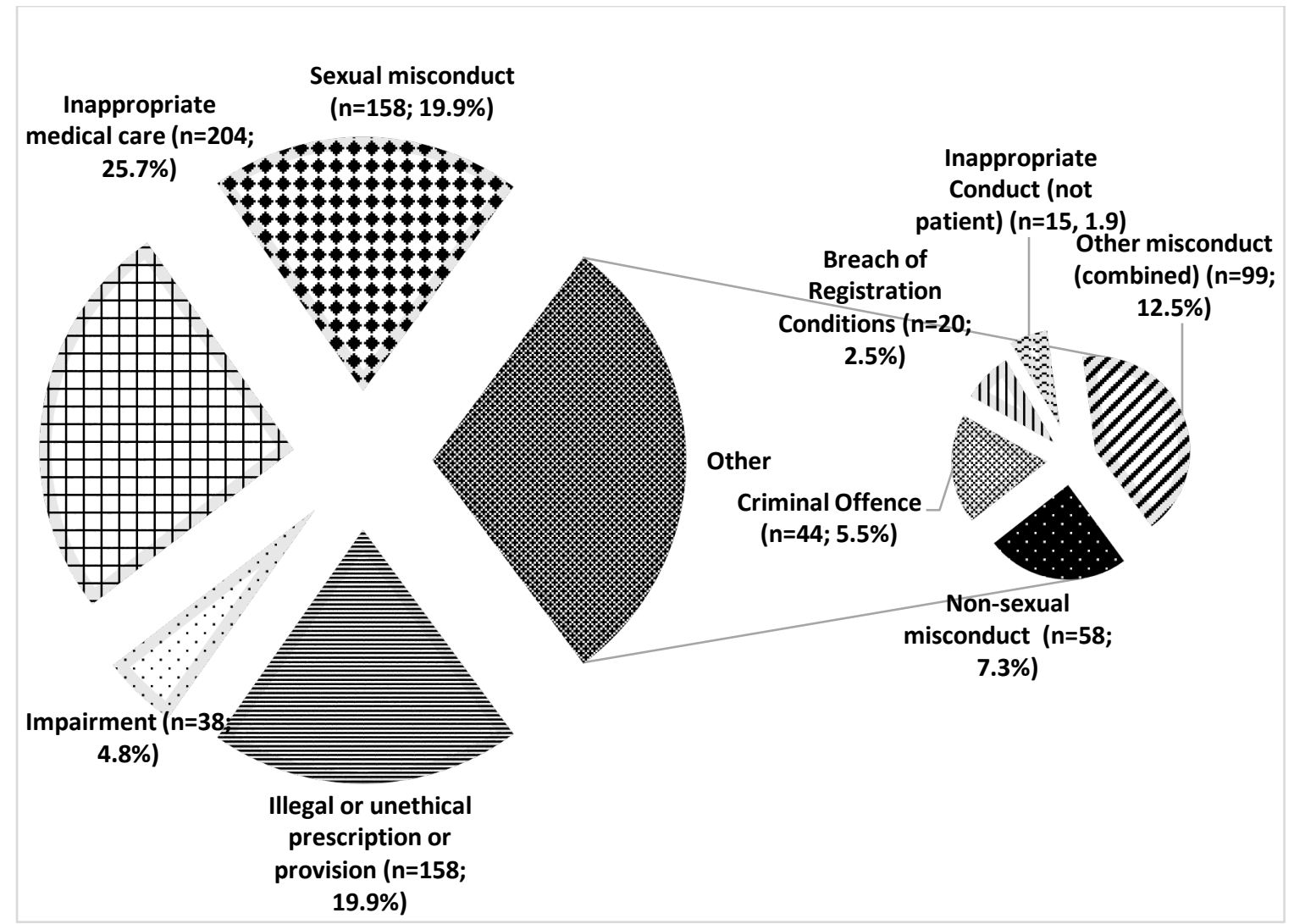

Figure 2: Main Head of Misconduct

The serious nature of the complaints is demonstrated by the fact that over a third of matters involved repeat incidents of misconduct, and nearly a fifth of decisions referred to associated criminal proceedings. ${ }^{35}$ Reflecting the fact that only the most serious matters are subject to a referral to disciplinary tribunals, the overwhelming majority of matters, 96.3 per cent ( $n$ 765), involved at least one head of the complaint being proved. Removal from practice was much more likely to occur for sexual misconduct than for inappropriate clinical care. ${ }^{36}$

Of proven cases, 55.8 per cent ( $\mathrm{n}$ 427) resulted in the respondent being removed from practice. Deregistration was ordered in 37.1 per cent of proven cases (n 284), and suspension

${ }^{35} 270$ cases ( 34 per cent) and 142 cases (18 per cent), respectively.

${ }^{36}$ See discussion in Jenni Millbank, 'Serious misconduct of health professionals in disciplinary tribunals under the National Law 2010-2017' forthcoming Australian Health Review. The same finding was made in a study of 371 UK medical disciplinary cases in 2009-2010, see: Paula Case, 'The Good, the Bad and the Dishonest Doctor: the General Medical Council and the 'Redemption Model' of Fitness to Practise' (2011) 31 Legal Studies 591, and in Elkin's study of Australian and New Zealand Tribunal decisions concerning doctors, discussed below. 
in 18.7 per cent (143). Identified discrepancies in outcome, discussed below, were much more pronounced in deregistration. A prohibition order, available only if removal from practice is ordered, occurred in only 6.3 per cent of proved cases. ${ }^{37}$

\section{Findings of the Present Study in the Context of Previous Australian and New Zealand Research on Misconduct}

Previous Australian research into health practitioner discipline has focused almost exclusively on doctors, with legal literature often focused upon high profile cases, ${ }^{38}$ or specific issues such as impairment, ${ }^{39}$ or prescribing offences; ${ }^{40}$ with a handful of works on particular medical specialties. ${ }^{41}$ There is very little research on the disciplining of the wide range of other health professionals apart from doctors. ${ }^{42}$

\footnotetext{
${ }^{37}$ Conditions were imposed on registration in just over half of proven cases ( $\left.\mathrm{n} 395\right)$, and the majority $(\mathrm{n} 218$ ) involved multiple conditions. In order of prevalence, conditions involved education/mentoring (n 237), restricted practice (n 142), supervision ( 120 ), counselling ( 71 ) and health conditions ( $n$ 47). As fines, cautions and reprimands could be issued in tandem with other orders, they were counted as 'non-restrictive' only when they were not imposed in tandem with a restrictive sanction such as deregistration: producing a rate of 'nonrestrictive' reprimand (32.4 per cent), caution (4.8 per cent) and fine (9.2 per cent).

${ }^{38}$ It is also notable that major legal inquiries into complaint mechanisms are frequently triggered by media attention concerning a repeat offender, most recently Andrew Churchyard and Emil Gayad: see Ron Paterson, Independent Review of the Use of Chaperones to Protect Patients in Australia (2017), discussed below at 81, and Gail Furness, Review of Processes Undertaken by the Medical Council of New South Wales Pursuant to Part 8 of the Health Practitioner Regulation National Law (NWS) with respect to Dr Emil Gayed (2018) $<$ https://www.mcnsw.org.au/medical-council-releases-final-report-gail-furness-sc-its-processes-respect-dremil-gayed $>$ respectively.
}

${ }^{39}$ Helen Kiel, 'Regulating Impaired Doctors: A Snapshot from New South Wales' (2013) 21 Journal of Law and Medicine 429.

${ }^{40}$ Danuta Mendelson, 'Disciplinary Proceedings for Inappropriate Prescription of Opioid Medications by Medical Practitioners in Australia (2010-2014)' (2014) 22 Journal of Law and Medicine 255; Danuta Mendelson, 'Disciplinary Proceedings against Doctors who abuse Controlled Substances' (2015) 23 Journal of Law and Medicine 24.

41 Freckelton, above n 1; Eleanor Dawson, 'Professional Misconduct in Psychiatry: Sexual Behaviour with Patients: A Report of recent New South Wales Findings' (2004) 28 Australian and New Zealand Journal of Psychiatry 197.

42 See, eg, Ryan, San Too, and Bismark, above n 24; Jenni Millbank et al 'Complementary Health Practitioners Disciplined for Misconduct in Australia 2010-2016’ (2017) 24 Journal of Law and Medicine 788. 
In the most significant study undertaken of Tribunal decisions prior to the National Law, Katie Elkin and colleagues gathered decisions concerning doctors from the four most populous States (NSW, Victoria, Queensland and WA), and also from New Zealand, for the 10 year period 2000-2009, and analysed outcomes for 485 matters. ${ }^{43}$ The major significance of the Elkin study was that it unpacked 'misconduct' to ask what actual kind of conduct was being addressed by Tribunals, as opposed to how the conduct is collected in complaint data, or how it is framed in the legislation, and how these different kinds of mconduct were adjudicated in terms of severity. ${ }^{44}$ Elkin et al found that 91 per cent of the respondent doctors were male. The outcome in 43 per cent cases was 'removal from practice' (comprising deregistration 28 per cent and suspension 15 per cent ), 37 per cent of matters resulted in conditions on practice and 19 per cent in non-restrictive action. ${ }^{45}$ The study found that sexual misconduct was far more likely to lead to removal from practice than failures of clinical care, ${ }^{46}$ and concluded that conduct which could be characterised as 'wilful wrongdoing' was more likely to lead to removal from practice. ${ }^{47}$ Despite some differences in methodology, ${ }^{48}$ and the wider coverage of other professions in this study, comparisons with the findings of the Elkin findings are useful in order to determine whether the kinds of matters in Tribunals, and outcomes, for doctors have changed following the National Law.

\footnotetext{
${ }^{43}$ Elkin et al above n 31; Katie Elkin et al, 'Removal of Doctors from Practice for Professional Misconduct in Australia and New Zealand' (2012) 21 BMJ Quality and Safety 1027 ('Removal of Doctors from Practice').

${ }^{44}$ See discussion in Elkin et al, 'Removal of Doctors from Practice', above n 38, 1027.

45 Elkin et al, above n 31, 454.

${ }^{46}$ Elkin et al, 'Removal of Doctors from Practice', above n 43, 1030.

47 Ibid.

${ }^{48}$ A limitation of the study was that the inclusion of New Zealand (which has had a unitary system with one Tribunal covering 21 different health professions since 2004) was not well explained in terms of whether the cases were genuinely comparable with the Australian cases. Another limitation was that 138 cases, representing a quarter of the entire pool of cases gathered, were excluded from analysis because the authors classified cases as 'non-disciplinary' if the issue was 'exclusively impairment'. Impairment may include physical or mental illness, cognitive decline or injury, substance addition, or a combination, often contributing to competence and performance issues, see discussion in Kiel, above $n$ 39. While a finding of impairment alone cannot lead to removal from practice under the National Law, it may lead to a related finding that the professional is not fit to practice, in which case removal is almost certain.
} 
In New Zealand, a study by Lois Surgenor and colleagues of 288 Tribunal decisions covering 21 health professions over a ten year period from 2004-2014 ${ }^{49}$ found that in 33 per cent of cases the outcome was deregistration, 30 per cent resulted in suspension and 61 per cent resulted in the imposition of conditions. ${ }^{50}$ When outcomes for nurses and doctors were compared, stark differences appeared: although suspension rates were comparable, doctors were considerably more likely to have conditions imposed than nurses ( 72 per cent versus 59 per cent), while nurses were almost twice as likely to be deregistered than doctors (44 per cent versus 23 per cent). However, that study did not categorise the kind of complaint, and instead focused on procedural factors (such as legal representation, the attendance of the practitioner at the hearing and whether the practitioner admitted guilt or not) to explore how these related to outcomes. The study noted that nurses were significantly less likely than doctors to have legal representation or attend the hearing, but offered no other analysis of why these outcomes differed so markedly. ${ }^{51}$ The present study sought to extend comparisons across professions, controlling for the type of misconduct and the impact of legal representation on outcomes.

Since the introduction of the National Law there has been a vastly increased ability to access centralised national complaint data. Bismark and colleagues have undertaken a number of retrospective studies of complaint data gathered by the Australian Health Practitioner Regulation Agency (AHPRA), and identified trends and risk factors across and within the regulated health professions. ${ }^{52}$ In a study of all notifications made to AHPRA during 2011 and 2012 (excluding NSW due to its separate processing of complaints) concerning the original 10

\footnotetext{
49 Lois Surgenor et al, 'New Zealand's Health Practitioners Disciplinary Tribunal: An Analysis of Decisions 20042014' (2016) 24 Journal of Law and Medicine 239.

${ }^{50}$ Some of these orders appear to be in combination: id 247.

51 The authors note the theory that 'low status' health professions many be punished more severely, but also suggest that another explanation could be found in the kind of misconduct in issue (which was not coded for) for instance if nurses had been involved in serial misconduct: id 249, 250.

52 See, eg, Marie Bismark et al, 'Identification of doctors at risk of recurrent complaints: a national study of healthcare complaints in Australia' (2013) 22 (7) BMJ Quality and Safety 532; Matthew Spittal et al, 'Outcomes of notification to health practitioner boards: a retrospective cohort study' (2016) 14 BMC Medicine 198; Ryan et al, 'Complaints about chiropractors, osteopaths, and physiotherapists: a retrospective cohort study of health, performance, and conduct concerns' (2018) 26(12) Chiropractic and Manual Therapies 1; Marie Bismark et al, 'Prevalence and characteristics of complaint-prone doctors in private practice in Victoria' (2012) 195(1) MJA 25.
} 
regulated professions, Spittal et al reported that the notification rate was highest among doctors and dentists and lowest among nurses and midwives. ${ }^{53}$ They reported that the likelihood of 'restrictive action' (a broad category which includes voluntary undertakings and conditions as well as suspension or deregistration) was higher for cases involving impairment, improper prescribing or use of medication, and sexual misconduct compared to cases involving clinical care. Doctors were less likely to face restrictive action than all of the other professions. Male practitioners were more than twice as likely as female practitioners to be the subject of a notification. The Bismark studies are an important point of reference in tracing whether trends in types of misconduct and severity of outcome across professions occur throughout the disciplinary system or are distinctive at Tribunal level.

The findings of the present study were broadly consistent with previous research on complaint data under the National Law and Tribunal cases prior to the National Law in that doctors were over-represented as respondents, nurses and midwives were underrepresented as respondents, male practitioners were greatly over-represented as respondents, failures in clinical care were the least likely type of matter to lead to restrictive action, and doctors faced less severe outcomes than other professions. This is significant in demonstrating that differential outcomes between professions under the National Law are occurring both at the level of Boards, which are dominated by each profession, and in external Tribunals which are chaired by a legal or judicial member.

Findings in the present study concerning doctors alone are also strikingly consistent with previous research by Elkin et al on outcomes for doctors appearing before Tribunals prior to the National Law. ${ }^{54}$ Concerns expressed by doctors' groups about the National Law, for example objecting to investigative processes and publicising powers of AHPRA, ${ }^{55}$ and to the

\footnotetext{
${ }^{53}$ Spittal et al, id.

${ }^{54}$ See Table 2 below for details of outcomes for doctors, in which the removal from practice rate is 3 per cent higher than in Elkin's study, but the deregistration rate is identical.

55 See, eg, Australian Medical Association, AMA submission to the Standing Committee on Community Affairs, Inquiry into the Complaints Mechanism Administered under the Health Practitioner Regulation National Law, February 2017 <https://ama.com.au/system/tdf/documents/AMA\%20Submission\%20to\%20the\%20Senate\%20Inquiry\%20int o\%20the\%20complaints\%20mechanism\%20march\%202017.pdf?file=1\&type=node\&id=46478>.
} 
scope of mandatory notification rules which had previously only applied in NSW, ${ }^{56}$ suggest that the National Law was perceived by some as a more onerous form of regulation of the medical profession. It is therefore of interest that, at Tribunal level at least, it has not produced a significant difference in terms of outcomes for doctors after seven years of operation. ${ }^{57}$

The distinctive and novel features of the present study involved comparing outcomes across the most populous professions and across all the Australian jurisdictions. Taking an overview of all outcomes in proved matters by profession, doctors were less likely than the other professions to be removed from practice across the period of the study. There were also significant differences in outcomes across the various jurisdictions, with NSW removing practitioners from practice at a higher rate than all others, while WA, Tasmania, the ACT and NT had very low removal rates. Variations by profession and by jurisdiction were both more acute when deregistration was taken as the focus. These variations, and possible explanations, are explored below.

\section{Variation in outcomes by profession}

A key finding was that doctors and dentists were less likely to be removed from practice than were nurses and pharmacists, and psychologists were more likely than all others to be removed. ${ }^{58}$

Table 2. Outcomes in Proved Matters by Profession

\begin{tabular}{|c|c|c|c|c|c|c|}
\hline $\begin{array}{c}\text { Proved } \\
\text { n 765 }\end{array}$ & $\begin{array}{c}\text { Dentists } \\
\mathbf{n ~ 5 1}\end{array}$ & $\begin{array}{c}\text { Doctors } \\
\mathbf{n ~ 3 0 1}\end{array}$ & $\begin{array}{c}\text { Nurses } \\
\text { \& Midwives } \\
\text { n 267 }\end{array}$ & $\begin{array}{c}\text { Pharmacists } \\
\mathbf{n ~ 7 5}\end{array}$ & $\begin{array}{c}\text { Psychologists } \\
\mathbf{n ~ 7 1}\end{array}$ & $\begin{array}{c}\text { Overall } \\
\text { outcomes }\end{array}$ \\
\hline $\begin{array}{c}\text { Removed from } \\
\text { practice }\end{array}$ & $49 \%$ & $46.1 \%$ & $61 \%$ & $60 \%$ & $77.5 \%$ & $55.8 \%$ \\
\hline
\end{tabular}

\footnotetext{
${ }^{56}$ See, eg, Australian Medical Association, AMA Submission, Mandatory Reporting, 29 September 2017 <https://ama.com.au/system/tdf/documents/AMA\%20Mandatory\%20Reporting\%20Submission\%20\%202018\%20Final\%20Submission.pdf?file=1\&type=node\&id=49613 $>$.
}

${ }^{57}$ And see a similar finding following a period of extensive review and reform of medical disciplinary institutions in the UK: John Chamberlain, 'Malpractice, Criminality, and Medical Regulation: Reforming the Role of the GMC in Fitness to Practise Panels' (2016) 25 Medical Law Review 1.

${ }^{58}$ Statistical significance between profession and removal from practice was established with a $p$ value of 0.0001 . 


\begin{tabular}{|c|c|c|c|c|c|c|}
\hline Deregistration & $37.2 \%$ & $27.9 \%$ & $45.7 \%$ & $30.7 \%$ & $50.7 \%$ & $37.1 \%$ \\
\hline Suspension & $11.8 \%$ & $18.2 \%$ & $15.3 \%$ & $29.3 \%$ & $26.8 \%$ & $18.7 \%$ \\
\hline $\begin{array}{c}\text { Prohibition } \\
\text { order }\end{array}$ & $2 \%$ & $2.3 \%$ & $7.1 \%$ & $9.3 \%$ & $19.7 \%$ & $6.3 \%$ \\
\hline Conditions & $58.8 \%$ & $53.5 \%$ & $43.8 \%$ & $66.7 \%$ & $52.1 \%$ & $51.6 \%$ \\
\hline $\begin{array}{c}\text { Supervision } \\
\text { Restricted } \\
\text { Practice }\end{array}$ & $9.8 \%$ & $17.6 \%$ & $10.5 \%$ & $12.0 \%$ & $35.2 \%$ & $15.7 \%$ \\
\hline
\end{tabular}

Variance between the professions in outcomes was noticeably more pronounced when deregistration was the outcome, with both nurses and psychologists being deregistered at considerably higher rates than doctors, and dentists also being deregistered at a rate greater than doctors despite their overall removal rate being fairly similar.

Examining removal from practice across the professions by reference to the type of proved misconduct the trend of less severe outcomes for doctors was consistent, particularly concerning deregistration, and particularly when doctors and nurses were compared. Within the main head of inappropriate clinical care, deregistration rates were: doctors (15.9 per cent), dentists (28.6 per cent), and nurses (36.2 per cent). ${ }^{59}$ Within the main head of prescription/provision of drugs, deregistration rates were closer: doctors ( 30 per cent), nurses (32 per cent) and pharmacists (37.3 per cent) (with no proven matters concerning dentists). Within impairment the numbers were small but the difference in deregistration continued: 45.5 per cent of doctors compared to 68 per cent of nurses.

Noting that sexual misconduct had by far the highest rate of removal from practice it could be regarded as the most 'serious' main head within the Tribunal setting. In Table 3 below, the figures for proved sexual misconduct are presented (Dentists n 8 and Pharmacists n 3 are excluded because their numbers were so small.) In this category nurses were almost twice as likely as doctors to be deregistered, however there were insufficient numbers to establish statistical significance. ${ }^{60}$ It is striking that, while on average deregistration was ordered twice

\footnotetext{
${ }^{59}$ Only three pharmacists had matters proved under this head and five psychologists (no pharmacists were removed from practice; four psychologists were deregistered).

${ }^{60}$ The $p$ value was 0.2052 .
} 
as often as suspension in proved sexual misconduct matters, and all professions were more likely to be deregistered than suspended for sexual misconduct, nurses were seven times more likely to be deregistered than suspended in the context of sexual misconduct. ${ }^{61}$

Table 3: Sexual misconduct outcomes by profession

\begin{tabular}{|c|c|c|c|c|}
\hline $\begin{array}{c}\text { Proved } \\
\text { n 150 }\end{array}$ & $\begin{array}{c}\text { Doctors } \\
\text { n 62 }\end{array}$ & $\begin{array}{c}\text { Nurses \& } \\
\text { Midwives } \\
\text { n 37 }\end{array}$ & $\begin{array}{c}\text { Psychologists } \\
\text { n 40 }\end{array}$ & $\begin{array}{c}\text { Overall } \\
\text { outcomes }\end{array}$ \\
\hline $\begin{array}{c}\text { Removed from } \\
\text { practice }\end{array}$ & $79 \%$ & $83.8 \%$ & $95.0 \%$ & $84.6 \%$ \\
\hline Deregistration & $48.4 \%$ & $73 \%$ & $57.5 \%$ & $58 \%$ \\
\hline $\begin{array}{c}\text { Suspension } \\
\text { Prohibition } \\
\text { order }\end{array}$ & $30.6 \%$ & $10.8 \%$ & $37.5 \%$ & $26.6 \%$ \\
\hline
\end{tabular}

Following Surgenor et al's suggestion that the presence of legal representation may be a factor in less severe outcomes ${ }^{62}$, this study examined the relationship between legal representation and outcome.

Firstly, it is notable that there was a major differential in legal representation by profession, presented in figure 3 below, with Doctors the most likely to have representation, and Nurses the least likely. ${ }^{63}$

Figure 3: Legal representation by profession

\footnotetext{
${ }^{61}$ The relationship between nursing and deregistration, as opposed to suspension, in the context of proved sexual misconduct was established as statistically significant with a $p$ value of 0.001 .

${ }^{62}$ Above $n 49$.

63 The relationship between profession and legal representation was tested for statistical significance, which was established with a $p$ value of 0.001 .
} 


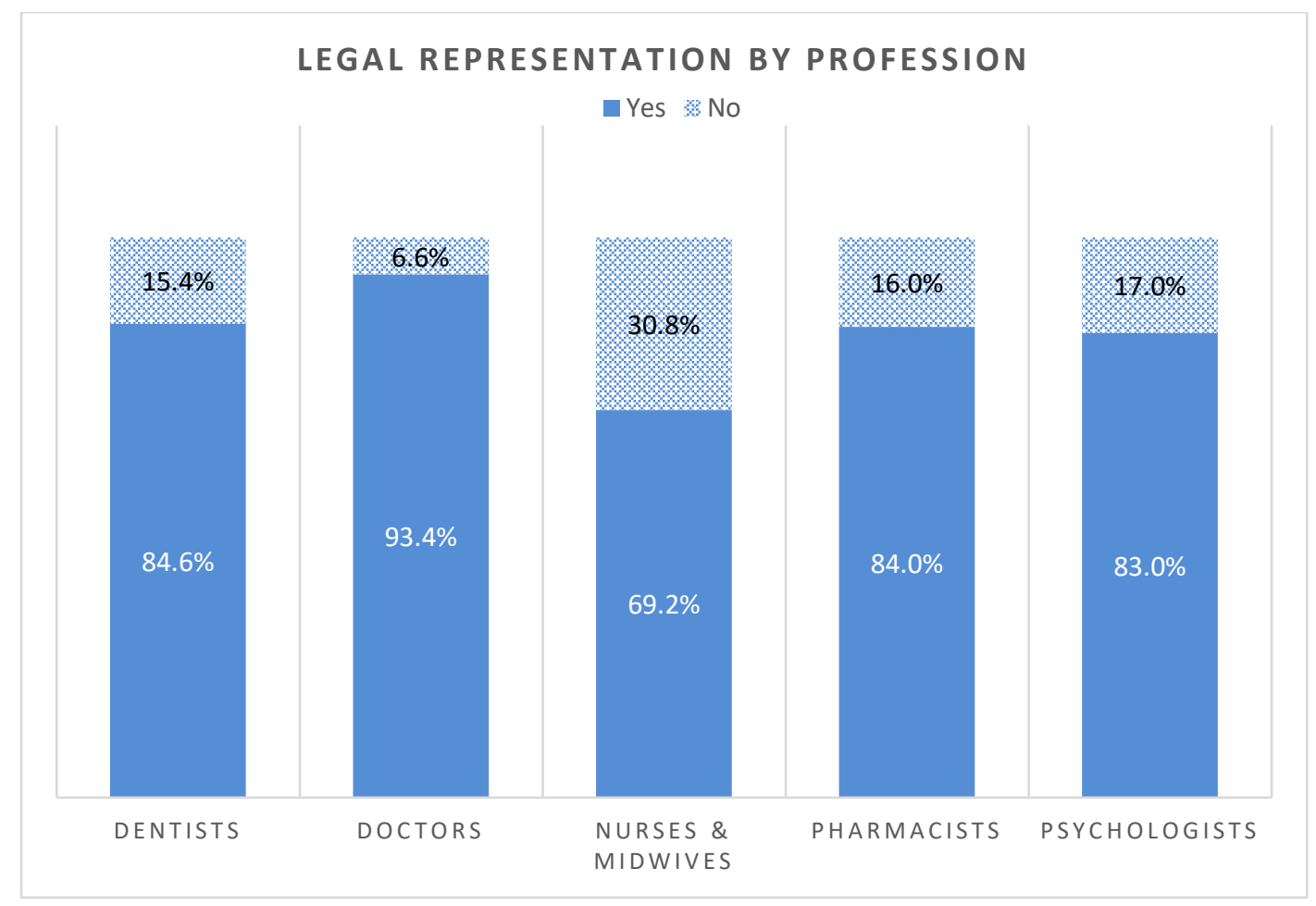

There was also a strong correlation found between the presence of legal representation at hearing and less severe outcomes. Among those with no legal representation there was an overall removal rate among proved matters of 77.7 per cent compared to 52.9 per cent for those with lawyers. This differential was again more acute when the outcome was deregistration, with proved matters leading to deregistration at more than twice the rate for those without lawyers compared to those who were represented, depicted in figure 4 below (and relatedly 7.1 per cent suspensions for those without lawyers compared to 22.9 per cent of suspensions for those who were legally represented). ${ }^{64}$

Figure 4: Deregistration and legal representation

\footnotetext{
${ }^{64}$ Statistical significance of the relationship between deregistration and legal representation was established with a $p$ value of 0.001 .
} 


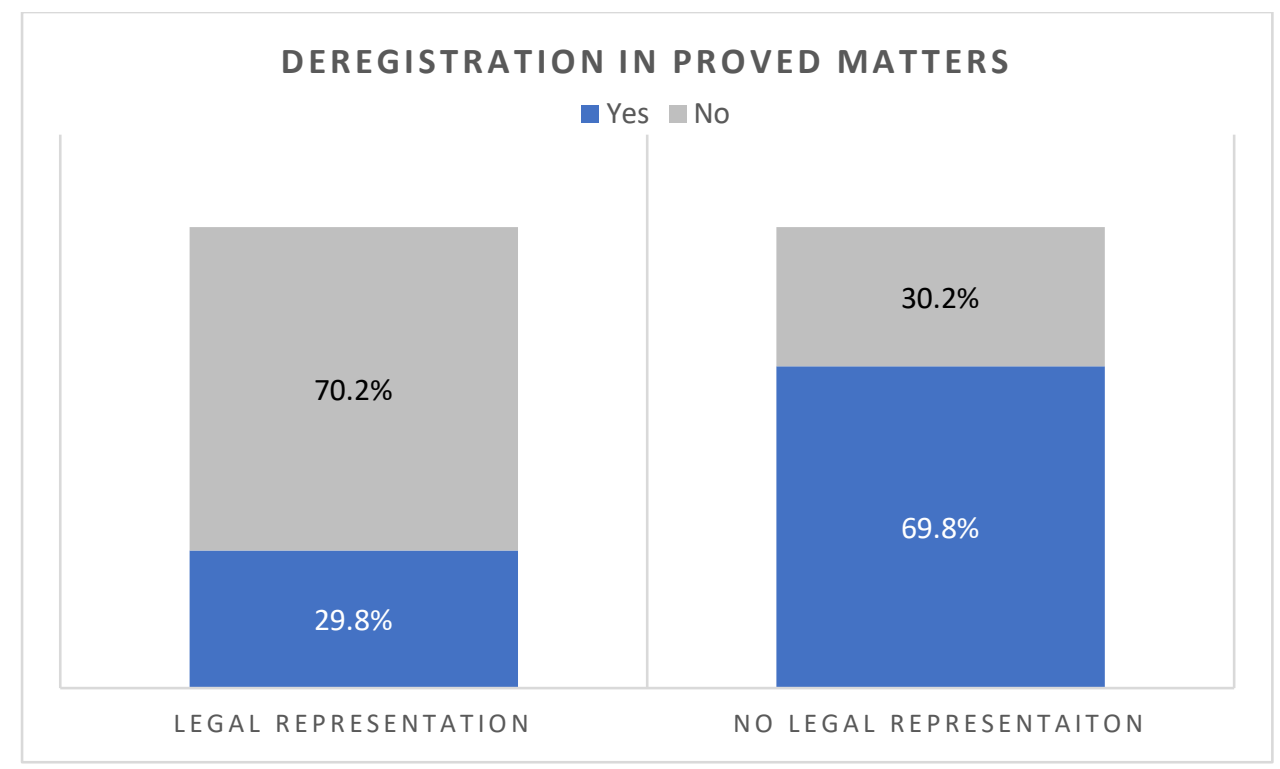

Yet even among those without legal representation, doctors were still removed from practice at a lower rate (66.7 per cent) compared to nurses and midwives (77.6 per cent), dentists (87.5 per cent) and psychologists (100 per cent). The exception was pharmacists without lawyers, who had a comparable removal rate to doctors, at 66.6 per cent.

Commentators such as Paterson, Elkin and Kiel have suggested that regulators and decisionmakers may place undue emphasis on the 'rehabilitation' of doctors at the expense of protection of the public. ${ }^{65}$ Paterson states:

The voice of the doctor, amplified by legal representation, is usually louder and more articulate than the voice of the patients, and it often seems that backing away from strong measures is the 'safer' approach. Furthermore harm to the practitioner, in the form of suspension, is immediate and quantifiable, while risk of harm to the public is distant and uncertain. ${ }^{66}$

Kiel notes that an often unarticulated premise of a rehabilitative focus is 'that society's investment in the education and training of doctors should not be lost' ${ }^{67}$ Elkin notes UK jurisprudence based on the notion that there is a particular public interest in rehabilitating

\footnotetext{
${ }^{65}$ See Keil, above n 34, 81. Cf Mendelson, 'Disciplinary Proceedings for Inappropriate Prescription', above n 40, arguing, based on her analysis of 32 prescription cases concerning doctors determined in Victorian and NSW Tribunals and Courts in the first 4 years of the National Law, that there is an undue focus on 'deterrence'.

${ }^{66}$ Ron Paterson, The Good Doctor: What Patients Want (Auckland University Press, 2012) 81.

${ }^{67}$ Kiel, above n $34,83$.
} 
medical practitioners that does not exist for other professionals whose skills are not unique or are in less demand. ${ }^{68}$ Elkin predicted that although 'supply considerations' appeared in some Australian Tribunal determinations prior to the National Law, the National Law 'granted permission' to focus on 'access' to the special skill of doctors (through object (e) 'to facilitate access to services provided by health practitioners in accordance with the public interest'). In her view this approach represents a 'slippery slope':

Quite simply: is access to a doctor who represents an elevated risk to the public preferable to having no doctor at all? ...[E]ven though there are concessions made at the point of registration, it is quite another matter to accept lesser standards once a doctor ...has demonstrated himself or herself to have fallen short. For this reason, while supply considerations may have relevance to registration decisions, we must be wary of taking them into account in making disciplinary decisions. ${ }^{69}$

While a looming crisis in supply of nursing professionals has been identified for some years, ${ }^{70}$ public interest considerations of supply appear to be rarely, if ever, argued in relation to nurses. Recollecting the high removal rates for sexual misconduct, I analysed the text of all decisions in the dataset where such misconduct was proved but the practitioner was not removed from practice. While determinations on the appropriate protective orders were a mix of complex factors, it is notable that the public interest in access to health services was explicitly reasoned exclusively in matters involving doctors. For example,

Dr Smith is a highly regarded medical practitioner in the field of paediatric neurology, in which there is significant demand and few practitioners. We note the numerous references provided in this proceeding on his behalf. There is a public interest in him continuing to be able to practice, subject to appropriate conditions. ${ }^{71}$

\footnotetext{
68 Giele v General Medical Council [2006] 1 WLR 942; discussed by Elkin, above n 11, 694. See also making available the 'special skills' of the doctor as one of the 12 factors considered regarding orders in WA jurisprudence: Medical Board of Australia v Veettil [2015] WASAT 124 and one of five factors considered in NSW: Health Care Complaints Commission v King [2013] NSWMT 9.

${ }^{69}$ Elkin, above n 11, 698.

${ }^{70} \mathrm{See}$, eg, Health Workforce Australia, Australia's Future Health Workforce - Nurses, Report (2014); Kathleen Calderwood and Greg Miskelly, 'NSW Needs Nurses as 'Catastrophic' Shortage Predicted to Affect Patient Care' ABC News (online), 12 Jan 2018, <https://www.abc.net.au/news/2018-01-12/nsw-set-for-major-shortage-ofnurses-and-midwives/9321464>.
}

${ }^{71}$ Medical Board of Australia v Smith [2016] VCAT 243, [27]. See also, eg, HCCC v Small [2012] NSWMT 18, [30]. 
Relatedly, among practitioners found guilty of sexual misconduct, only doctors were returned to practice under so-called 'chaperone' conditions, which were not applied to any other professional group. ${ }^{72}$ This analysis suggests that the lower rates of deregistration of doctors compared to other practitioners, in particular nurses, found in this study cannot be explained objectively by reference to the public interest in access to health services, but perhaps by a subjective sense that their skills are of greater value.

When invited to comment on the findings, one Tribunal health division head suggested that there may be a divergence in practice among the different professional Boards, in that some Boards were more likely than others to apply for and argue for deregistration in the Tribunal setting. In that member's view, the Medical Board was less likely to pursue deregistration than many of the other professions, and this prosecutorial position could be reflected in different patterns of outcome.

Arguably the kind of wide variation in outcomes across professions identified in this study has no basis in law or explanation consistent with the objective of the National Law. These disparities should be explored in further detail to determine the impact of investigation, referral and decision-making processes and cultures, including the role of unconscious bias in such processes.

\section{Variations in outcome by jurisdiction}

Another major finding of the study was that there were significant variations in outcomes across the jurisdictions. ${ }^{73}$ For example, deregistration was ordered in NSW more than five times as often as it was in the ACT, Tasmania and NT combined, and around twice as often as in the other states combined. The greater severity of outcomes in NSW is underscored by its far higher rate of prohibition orders (which prevent the practitioner from undertaking any or all of a broad range of other unregistered health services) compared to SA and WA; and the

\footnotetext{
72 See below note 82 and accompanying text.

73 The relationship between jurisdiction and deregistration was established as statistically significant with a $p$ value of 0.0001 .
} 
fact that other jurisdictions issued none of these types of orders at all over the seven-year period. See Table 4 below.

Table 4. Removal from practice by jurisdiction

\begin{tabular}{|c|c|c|c|c|c|c|c|}
\hline & $\begin{array}{c}\text { ACT, Tas } \\
\text { and NT } \\
\text { Combined } \\
\mathbf{n ~ 3 7}\end{array}$ & $\begin{array}{c}\text { SA } \\
\mathbf{n ~ 6 5}\end{array}$ & $\begin{array}{c}\text { Qld } \\
\mathbf{n ~ 1 3 0}\end{array}$ & $\begin{array}{c}\text { WA } \\
\mathbf{n ~ 1 5 4}\end{array}$ & $\begin{array}{c}\text { Vic } \\
\mathbf{n ~ 1 1 2}\end{array}$ & $\begin{array}{c}\text { NSW } \\
\mathbf{n ~ 2 6 7}\end{array}$ & $\begin{array}{c}\text { Overall } \\
\text { Proved } \\
\mathbf{n} \mathbf{7 6 5}\end{array}$ \\
\hline $\begin{array}{c}\text { Removed from } \\
\text { practice }\end{array}$ & $37.8 \%$ & $58.5 \%$ & $59.2 \%$ & $40.9 \%$ & $52.6 \%$ & $65.9 \%$ & $55.8 \%$ \\
\hline Deregistration & $10.8 \%$ & $30.8 \%$ & $25.4 \%$ & $25.3 \%$ & $30.3 \%$ & $57.7 \%$ & $37.1 \%$ \\
\hline Suspension & $27 \%$ & $27.7 \%$ & $33.8 \%$ & $15.6 \%$ & $22.3 \%$ & $8.2 \%$ & $18.7 \%$ \\
\hline Prohibition order & $0 \%$ & $7.7 \%$ & $0 \%$ & $3.2 \%$ & $0 \%$ & $14.2 \%$ & $6.3 \%$ \\
\hline
\end{tabular}

While Queensland had a removal rate comparable to NSW, it was the only major jurisdiction in which suspension was ordered more often than deregistration.

It is very hard to explain this degree of variation of outcome under the National Law. Recollecting that lack of legal representation was strongly associated with more severe outcomes, in particular deregistration, data was disaggregated to examine whether there was also jurisdictional variation in legal representation. Rather surprisingly there was considerable variation in proportions of legally represented respondents across the states: from a high of 96 per cent in WA to a low of 73 per cent in NSW. The other jurisdictions were clustered closer to the average ( 83 per cent) with 87 per cent of practitioners legally represented in Qld and Victoria, and 79 per cent in SA and also in NT, ACT and Tas combined. However, these variations in legal representation don't map neatly against outcomes, with some of the lowest rates of deregistration appearing in jurisdictions with low rates of legal representation (SA, ACT, Tas and NT), and WA and Qld having almost identical rates of deregistration despite having different levels of legal representation. Only NSW had a clear correlation between a high rate of deregistration and low rate of legal representation.

Recollecting that outcomes were highly variable depending upon the main head of misconduct, data on type of misconduct was also disaggregated by jurisdiction. While the spread of matters across the jurisdictions for illegal or unethical prescription or provision of drugs, inappropriate clinical care and the other misconduct category was consistent, there were notable variations when it came to impairment and sexual misconduct. Of a total of 38 
matters concerning impairment, 28 were determined in NSW and 6 in WA, with two in Qld, one in each of the ACT and SA, and none at all in Victoria, Tasmania and the NT, suggesting that the issue of competence to practise is more likely to be dealt with at Tribunal level in NSW and WA compared to the other jurisdictions.

The proportion of sexual misconduct matters was similar in Tribunals of the most populous states, NSW and Queensland (23 per cent) and Victoria (29 per cent) but much lower in the others: making up only 11 per cent of matters in WA, 9 per cent in South Australia and 13 per cent in ACT, NT and Tasmanian combined. However, this variation again does not map neatly onto outcomes, as for example Victoria and South Australia had almost the same rate of deregistration, despite that fact that Victoria had more than three times the proportion of sexual misconduct matters and so could reasonably be expected to have a higher rate of deregistration. Rather than solving a question on variation of outcome, this data provokes more questions - in particular whether there is an underlying difference across the states in terms of the practice of the National Boards, and beyond that within the professions themselves, in terms of whether and when they refer sexual misconduct matters to Tribunals within disciplinary processes.

Queensland and NSW have unique legislative features in that their versions of the National Law place protection of the public as a 'paramount' objective'. While this could contribute to higher levels of removal from practice in those two jurisdictions compared to others, it cannot account for the differences between them - notably that deregistration is ordered twice as often in NSW compared to Queensland; as well as the dramatically different rates of suspension and prohibition orders when comparing these states.

The most distinct structural difference between jurisdictions is that NSW and more recently Queensland are 'co-regulatory' under the National Law. In NSW this means that complaints go first to a state based 'Council' (which acts in the same role as the National Board on disciplinary issues) and are prosecuted by a stand-alone agency, the Health Care Complaints Commission (HCCC). The HCCC pre-dates the National Law and prosecutes complaints using 
in house lawyers and private counsel. ${ }^{74}$ In Queensland since 2014 there is a stand-alone complaints agency, the Health Ombudsman, but complaints can still be brought to the Tribunal by the relevant National Board, or by the Ombudsman, which acts as the complainant before the Tribunal. ${ }^{75}$ There have been suggestions that NSW may take a more robust approach to disciplinary matters as a result of these institutional and cultural differences. ${ }^{76} \mathrm{It}$ remains to be seen whether the shift to a state-based complaints agency will impact upon outcomes in Queensland.

In a recent survey study of Tribunal decision-makers and personnel involved in disciplinary hearings by Chiarella et al there were 75 respondents in all, 38 from NSW and 37 from elsewhere in Australia, and responses were compared from these two groupings. ${ }^{77}$ All respondents were given the same vignette drawn from a UK disciplinary case and asked whether it raised questions of fitness to practise. In response to a question about whether the matter should be referred to a Tribunal (recollecting that prima facie de-registrable conduct must be referred under the National Law) there was divergence across the groups: with 49 per cent of respondents from outside NSW stating that it should be referred compared to 63 per cent of those from NSW. Relatedly, while five respondents from outside NSW did not view the case study as raising any fitness to practise issues, only one from NSW came to that conclusion. However, there was no clear difference between the groups in terms of their choice of outcome. ${ }^{78}$ The authors concluded that

\footnotetext{
${ }^{74}$ See discussion in Wolf above $\mathrm{n} 1$.

${ }^{75}$ See Office of Health Ombudsman, Queensland: https://www.oho.qld.gov.au/about-us/office-of-the-healthombudsman/ (accessed 22 March 2019), see also above $n 7$.

76 One division head noted that in that jurisdiction, the National Board briefs external solicitors to pursue Tribunal complaints and those solicitors are sometimes new to the health jurisdiction, compared to NSW where in house lawyers are, in effect, repeat players with deep institutional knowledge.

${ }^{77}$ Chiarella et al, above n 15.

${ }^{78}$ Both groups had similar rates of response favouring conditions and reprimands: ibid, 372.
} 
there were no significant differences between [NSW and the other cohort] in the way decision-makers approached the case. This is a good result in relation to minimising variation in decision-making across Australia. ${ }^{79}$

The cohort in the Chiarella study was small, addressed only one case study, and the analysis did not compare views between the other states; it is hard to know whether its findings can be generalised.

Bismark et al's work on mandatory notifications (recollecting that these also are an indicia of seriousness) suggests dramatic differences in approach between the culture of health practitioners in relation to regulation in different jurisdictions. In a retrospective study of 819 mandatory notifications from all jurisdictions except NSW made over a 1-year period early in the National Law (from November 2011), Bismark found Victoria had a report rate of less than 20 per 10,000 practitioners, while Queensland had a rate of 40 and SA over $60 .{ }^{80}$

Similarly, in a 2017 review of the appropriateness of the use of so-called 'chaperone' conditions to facilitate the continued practise of doctors accused of (and on occasion, conclusively proved to be guilty of) sexual misconduct, Paterson noted inconsistent approaches of Medical Board committees across the states and territories (and even within differently constituted committees within a single jurisdiction) in terms of response to serious allegations. ${ }^{81}$ Paterson suggested that,

This may reflect changing membership of Board committees and differing advice from AHPRA staff in local office, possibly influenced by varying signals from responsible tribunals. ${ }^{82}$ (emphasis added)

\footnotetext{
79 Ibid, 376.

${ }^{80}$ Marie Bismark, Matthew Spittal, Tessa Plueckhahn, David Studdert, 'Mandatory Reports of Concerns About the Health, Performance and Conduct of Health Practitioners' (2014) 201 Medical Journal of Australia 399, 402.

${ }^{81}$ Ron Paterson, above n 33, 77.

82 Ibid. For cases in which Tribunals ordered conditions involving 'chaperones' following findings of sexual misconduct against doctors, see eg: Medical Board of Australia v Veettill [2015] WASAT 124; Medical Board of Australia v Blomeley [2014] QCAT 160; HCCC v Vastrad [2011] NSWMT 1. See also Medical Board of Australia $v$ Young [2010] VCAT 1542 in which the doctor was practising under a condition imposed by the Medical Board in 2003 that he not have sex with any patient; a condition strongly suggestive that such an event had occurred previously. This condition was subsequently breached.
} 
Variation between jurisdictions should not be reduced to understandings of 'severity' alone, but rather as the product of a more complex interplay of institutional and cultural factors. The present study also found considerable differences across the various jurisdictions in nonrestrictive outcomes, particularly the frequency at which fines were ordered, and also in the incidence of non-disciplinary orders such as costs.

The National Law introduced fines of up to $\$ 30,000$ payable to the National Board as a possible outcome. ${ }^{83}$ The rate of fines ordered in proven matters varied from almost none in NSW and Queensland (1.8 per cent and 1.5 per cent, respectively) to a quarter of cases in South Australia and over a third in Western Australia. ${ }^{84} \mathrm{~A}$ low rate of fines in NSW is explicable by reference to legislative variation, as the NSW law provides that a fine can only be ordered if it has not already been imposed by a court and if the Tribunal is satisfied there is no other order, or combination of orders, that is appropriate in the public interest. ${ }^{85}$ However all other jurisdictions adopted the National Law provision without amendment.

Costs were awarded against the practitioner in 58.7 per cent of proved cases overall, yet this varied from a low of 29.7 per cent of cases in the ACT, NT and Tasmania combined, to 40 per cent in SA and Victoria, over 70 per cent in NSW and Queensland, and a high of 91 per cent in WA. Again this disparity cannot be explained by reference to legislative provisions, as the National Law provides a discretion to the responsible tribunal to make any order as to costs that it 'considers appropriate' and all jurisdictions adopted this. ${ }^{86}$

Differences in the culture and practice of the various state and territory Tribunals should not be underestimated. ${ }^{87}$ It appears that the WA Tribunal releases decisions involving practitioner

\footnotetext{
${ }^{83}$ Health Practitioner Regulation National Law Act 2009 (Qld) s 196(2)(c).

${ }^{84}$ SA was 24.6 per cent, WA was 36.4 per cent. The ACT, NT and Tas combined were 5.4 per cent.

${ }^{85}$ Health Practitioner Regulation National Law 2009 (NSW) s 149B.

${ }^{86}$ National Law s 195.

87 The Queensland, South Australian and Victorian Tribunals on occasion reduce or remove entirely periods of suspension based upon a 'time served' approach, crediting the period of time passed in which some practitioners had been unable to practice prior to the hearing by reason of immediate action taken at Board level: see e.g. Medical Board of Australia v Leggett [2015] QCAT 240; Medical Board of Australia v Gale [2015] SAHPT 3; Psychology Board of Australia v Huson [2013] VCAT 145. While these variations of practice merit further exploration, they can only explain differences in the length of suspensions ordered across jurisdictions (which
} 
undertakings and agreed conditions that would likely be finalised at Board level elsewhere. ${ }^{88}$ However such variation cannot explain the deregistration rate in WA, which is comparable to SA and Queensland. In a similar vein, the Victorian, ACT and Queensland Tribunals commonly accept joint submissions on protective orders by consent (which the ACT also encourages by way of ordering mediation between the parties). Although the Tribunal still has to be satisfied that the orders are appropriate in the circumstances, it is possible that this practice contributes to lower deregistration rates in those jurisdictions ${ }^{89}$ (as well as lower deregistration rates for the professions whose Boards seek lesser penalties).

While one may not expect absolutely uniform approaches to the National Law across different state and territory Tribunals, this study found a number of areas of inconsistency in outcomes, including the most serious form of outcome (deregistration and prohibition), and major disparities in other forms of outcome, without being able to identify a cogent basis for most of them.

\section{Conclusion}

This is not a study of the prevalence or incidence of kinds of misconduct within the health professions. Rather it is an analysis of how such conduct appears and is responded to in the principal legal fora in which it appears - the disciplinary tribunal.

In an independent review of the National Law in 2014, Snowball noted that,

\footnotetext{
were not compared in this research), not differential rates of deregistration. The Queensland Tribunal also appears to have unique practices concerning suspension orders; for some years it ordered suspension and then 'suspended' part or all of that order as long as conditions were complied with: see eg Medical Board of Australia $v$ Yasin [2011] QCAT 300. This was later determined to be a form of order not authorised by the National Law: see eg Psychology Board of Australia v Cook [2014] QCAT 162.

88 This practice would contribute to both the high number of finalised cases and the low rate of removal from practice in WA.

${ }^{89}$ See discussion of the deference of the Tribunal to such 'suggested determinations' in Medical Board of Australia v McGrath [2014] VCAT 641 at [18]-[21].
} 
[A] number of stakeholders raised concerns that the use of jurisdictional Tribunals may result in different processes, different decisions or penalties for the same offence, leading to the possibility of increasing numbers of appeals and the application of different principles in considering cases. However there was little evidence presented to support the assertions. ${ }^{90}$

This research provides such evidence. Major disparities were identified in outcomes across the professions, even when matters concerned the same main head of misconduct, with doctors consistently facing less severe outcomes, especially in lower rates of deregistration. Different levels of legal representation alone were insufficient to account for these disparities. Nor can the 'public interest' in access to health services account for disparate rates of deregistration. Demonstrated shortages of nurses did not translate into explicit consideration of this factor for nurses facing removal from practice in a sample of sexual misconduct cases examined, nor indeed was it addressed for any profession other than doctors. There is no legislative justification for such differential outcomes between health professions, which must be examined in future work as a product of cultural and institutional factors that have produced a bias in favour of retaining doctors in practice.

Marked differences were also identified in outcomes across the jurisdictions. Deregistration rates were much lower in ACT, Tas, NT, somewhat lower than the overall average in Qld, WA, SA and Vic, and markedly higher in NSW. Prohibition orders were not utilised at all in the ACT, Tas, NT, Queensland and Victoria, were used at a low rate in WA and really only appeared to be a significant feature in SA and NSW. In contrast, fines which were barely used elsewhere were commonly ordered in SA and WA. It also appeared that there were differential rates of referral of some kinds of matters to Tribunals, as sexual misconduct cases appeared in strikingly different ratios across the states and territories, with notably lower numbers of such cases in WA, SA, the NT, ACT and Tas compared to the more populous states. There is again no explanation to be found in the legislation for these trends.

\footnotetext{
${ }^{90}$ Kim Snowball, Independent Review of the National Registration and Accreditation Scheme for Health Professions (2014) at 68. http://www.coaghealthcouncil.gov.au/Publications/Reports/ArtMID/514/ArticlelD/68/The-IndependentReview-of-the-National-Registration-and-Accreditation-Scheme-for-health-professionals The reviewer consulted with the Tribunals and determined that the publication of decisions, annual meeting of the heads of the jurisdictions, and internal training processes comprised 'adequate processes in place to minimise the risk of different decisions between the jurisdictions on the same or similar matters': Id at 69.
} 
The National Law was intended to unify a fragmented and inconsistent health regulation landscape in Australia. Despite the organisational complexity engendered by the coregulatory jurisdictions, the substantive law applied through the National Law is, with limited and mostly minor variations, genuinely national. The first object of that National Law is to provide for the protection of the public by ensuring that only competent and ethical health practitioners are registered to practise. It is a reasonable expectation that such protection of the public would be consistently exercised by Tribunals applying the National Law - yet this study demonstrates that this is not so. In crude terms, a nurse is almost twice as likely as a doctor to be deregistered as a consequence of a disciplinary determination of a Tribunal, and any health practitioner appearing before a disciplinary tribunal in NSW is more than twice as likely to be deregistered in NSW compared to the other mainland states.

While some level of variation in local practice is to be expected in any national regime administered in a devolved set of institutions such as state Tribunals, the areas of divergence identified in this study represent significant and continuing inconsistencies that lack any comprehensive explanation. Long term trends showing major and unexplained anomalies should give cause for concern as to whether the National Law is a genuinely national scheme offering reliable and consistent protection to the public in all forms of health treatment and all locations, as well as parity of treatment between respondent practitioners.

It is suggested that a number of measures could be explored in order to better understand the underlying reasons for variation and to then develop shared understandings of areas where greater consistency could, and should, be achieved. Enhanced training and coordination between Tribunals and other disciplinary agencies including National Boards, Board Committees, NSW Councils, the Queensland Office of the Health Ombudsman and AHPRA $^{91}$ would facilitate these objectives. Such a process would also assist to develop clearer guidance on, and better common understanding of, what conduct should be considered as prima facie of such seriousness as to require referral to Tribunal level. It is further suggested

\footnotetext{
91 Id at 69.
} 
that serious consideration could be given to the development of qualitative 'sanctions guidance', such as that in use in the UK in medical matters, for use in all Tribunals. ${ }^{92}$

92 General Medical Council, Sanctions Guidance: For Members of Medical Practitioner Tribunals and for the General Medical Council's Decision Makers (2018) https://www.mpts-uk.org/-/media/mptsdocuments/DC4198 Sanctions Guidance Feb 2018 23008260.pdf 